W S R C - T R - $94-022$

\title{
DORT Certification Package
}

Task Number: 93-044-1

ROBERT L. FROST

January 1994
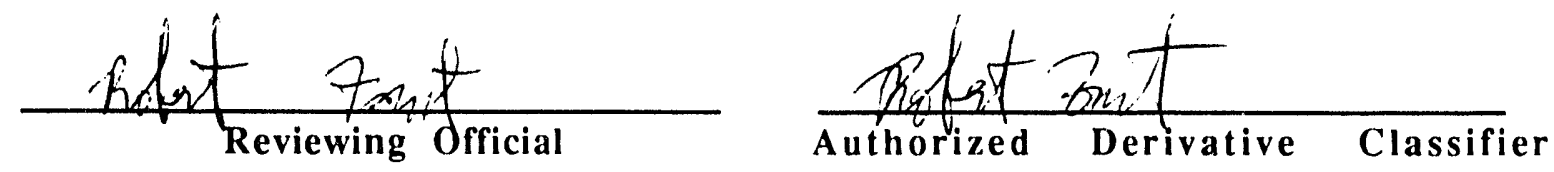

WESTINGHOUSE SAVANNAH RIVER COMPANY SAVANNAH RIVER TECHNOLOGY CENTER AIKEN, SC 29808

PREPARED FOR THE U. S. DEFARTMENT OF ENERGY UNDER CONTRACT DE - AC09-89SR18035

DISTRIBUTION OF THIS DOCUMENT IS UNLIMITED 


\section{DISCLAIMER}

This report was prepared by Westinghouse Savannah River Company (WSRC) for the United States Department of Energy under Contract DE-AC0989SR18035 and is an account of work performed under that Contract. Neither the United States, the United States Department of Energy nor WSRC, nor any of their employees, makes any warranty, express or implied, or assumes any legal liability or responsibility for the accuracy, completeness, or usefulness of any information, apparatus, product, or process disclosed herein, or represents that its use will not infringe privately owned rights. Reference herein to any specific commercial product, process or service by trade name, mark, manufacturer, or otherwise does not necessarily constitute or imply endorsement, recommendation, or favoring of same by WSRC or by the United States Government or any agency thereof. The views and opinions of authors expressed herein do not necessarily state or reflect those of the United States Government or any agency thereof. 
WS R C - TR.94-022

Task 93-044-1

KEYWORDS:

DORT

Certification

Discrete Ordinates

Transport Theory

Shielding

Criticality

Retention-Permanent

DORT Certification Package

B y

ROBERT L. FROST

ISSUED: January 1994

SRTC SAVANNAH RIVER TECHNOLOGY CENTER, AIKEN, SC 29808 Westinghouse Savannah River Company Prepared for the U. S. Department of Energy under Contract DE-A C09-89SR 18035 
Document: $\quad$ WSRC-TR-94-022

Title: DORT Certification Package

Task Number:93-044-1

Task Title: Certification of TORT, DORT, and MORSE-CGA

APPROVALS

$\frac{(i(1)(1, i) /}{\text { R.E. Pevey, Technical Reviewer }} \quad$ Date: $1 ;$

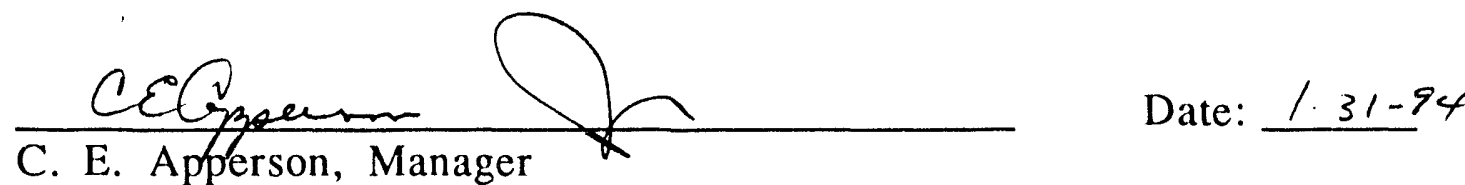

Applied Physics Group

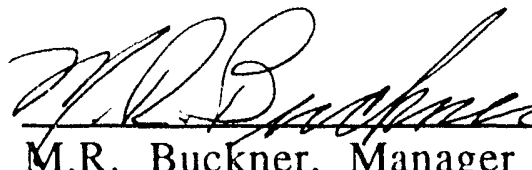

Date: $2-1-94$

Applied Technology Section 
ABSTRACT

The DORT code has been certified. DORT is a two-dimensional discrete ordinates transport theory code, that can solve neutron, photon, or coupled neutron/photon problems. It is anticipated that DORT will be used for criticality calculations as well as for shielding and radiation field analysis at SRS. In addition to the DORT module itself, 5 utility programs that are useful in certain DORT applications have been certified. These modules are: GIP, DOS, GRTUNCL, BNDRYS, and RTFLUM. As defined in this work, certification does not imply validation. These codes must be validated for a particular type of calculation before they can be used for critical applications.

\section{DISCLAIMER}

This report was prepared as an account of work sponsored by an agency of the United States Government. Neither the United States Government nor any agency thereof, nor any of their employees, makes any warr. nty, express or implied, or assumes any legal liability or responsibility for the accuracy, comrieteness, or usefulness of any information, apparatus, product, or process disclosed, or represent: that its use would not infringe privately owned rights. Reference herein to any specific commercial product, process, or service by trade name, trademark, manufacturer, or otherwise does not necessarily constitute or imply its endorsement, recommendation, or favoring by the United States Government or any agency thereof. The views and opinions of authors expressed herein do not necessarily state or reflect those of the United States Government or any agency thereof. 


\section{INTRODUCTION AND SUMMARY}

In response to a Department of Energy (DOE) request, Westinghouse Savannah River Company committed to certify all computer codes used in critical calculations at the site. The DORT code will be used to perform critical calculations related to shielding and nuclear criticality safety, and therefore must be certified.

Certification as applied to existing computer codes includes the verification process, placing the code in configuration control, and establishing user qualification standards and training requirements. All software intended for use in critical calculations must be certified. This report is intended to fulfill the requirements for the certification of the DORT code, source version 2.6.5 (released Jan. 5, 1993), built at SRS March 5, 1993, by H.L. Harris (executable version 1.0).

The reader should note that certification as defined here does not include the validation process. In the past, work performed by the Applied Physics Group was directly related to reactor safety or performance. This relatively narrow scope meant that defining validation requirements that would encompass all uses of the code was possible. (This is not to say that performing such analyses was easy, only that it was possible to define what was needed in advance.) In our new environment, APG performs criticality and shielding analyses. The variaty of geometries, materials, and systems encountered is innumerable. For this reason, task plan 93-044-1 specified that the TORT, DORT and MORSE-CGA codes would be certified without validation. Validation will subsequently be performed for specific tasks that the codes are to be used for, using certified software. Thus certified software will be validated for specific tasks.

Certification does imply that the code has been verified, placed in configuration management, and that all applicable documents as required in 1Q34 have been approved. Verification is accomplished by running the test problems included with the code, and comparing the results to those provided with the source code. Verification is documented in the test problem report.

This work was performed under STD QA task number 93-()44-1, Certification of TORT, DORT and MORSE-CGA, and follows the requirements of QAP IV-9 of 1Q34. 


\section{DISCUSSION}

\section{Application}

DORT is a two-dimensional transport theory code that uses multigroup cross sections and employs discrete ordinates theory to solve the neutron flux as a function of position, energy group, and direction. It can solve neutron, photon, or coupled neutron/photon problems. The code was written by W.A. Rhoades and R.L. Childs at Oak Ridge National Laboratory.

The DORT code was developed primarily to solve shielding problems in one or two dimensions. It is used routinely at Oak Ridge National Laboratory for that purpose. At SRS, it is anticipated that DORT will be used for analysis of evacuation zones in the vicinity of nuclear incident monitor alarms. In addition, DORT will most likely be used in various nuclear criticality safety applications. While DORT was written with shielding applications in mind, it is capable of accurately solving criticality problems as well, albeit perhaps not as efficiently as codes that have been optimized for this purpose (e.g., TWODANT). Other applications for DORT at SRS will almost surely arise in the future.

In addition to the DORT program itself, five utility programs that come with the DORT package distributed by RSIC have been certified. A brief description of each of these codes will be given. GIP (Group organized cross section Input Program) reads nuclide-organized cross section data (as produced by the AMPX77 system) and then writes a group organized cross section file. DORT requires input cross sections to be in the GIP format, so this code is required to process cross sections for any DORT calculation. DOS (Discrete Ordinates System) is a simple driver code, that allows one to combine input for DORT and any of its utility programs into a single input file. The BNDRYS code reads an internal boundary flux file and writes an internal boundary source file. This can be very useful for coupling DORT calculations. RTFLUM is a code for converting, expanding, and editing standard data files. Its primary purpose is to provide conversion between flux moment files in the DOTIII, VARFLM, and RTFLUX formats. It is anticipated that this module will not be needed for most studies at SRS. The final utility code is GRTUNCL, a first collision source code. It is used to mitigate ray effects in DORT calculations by providing a first collision source, distributed throughout the entire geometry, from a point or ring source. 


\section{Input}

Input data is contained in a single file in card image format. The DORT code uses the FIDO input processor, which eases the input description for large arrays of data. This input file supplies data on geometry, sources, and mesh spacing, as well as computational options, convergence criteria, and output edit instructions. A complete discussion of the input requirements is given in Ref. 1 .

The code also requires a file containing all cross sections used in the problem. These cross sections must be in group organized format, as is produced by the GIP processing code. A third file containing boundary or distributed source information is optional. Typically, this file is produced as output from a previous DORT problem, or from the utility codes RTFLUM, BNDRYS, or GRTUNCL.

\section{Output}

The output from a DORT run depends to a large extent on the edit options requested in the input. An echo of the input selections is always printed as the first item. This is followed by a detailed edit of the space meshing, and a set of zone plan views. The latter presents a mapping of the material number as a function of the fine mesh position. It is used to confirm the geometry input is as intended. If selected in the input, the next item to be printed is a multigroup cross section edit. The results of the calculation are printed next. Information on convergence and acceleration effectiveness as well as the current value of k-effective is printed for each source and flux iteration. The flux results can be printed after each iteration or only after the calculation has converged, depending on input selection. Flux edits can be requested for every mesh cell or only for selected "key" cells. Simple activity edits can be requested as well. These edits involve an automatic integration over energy before multiplication by the user input factor, and are thus much less powerful than the response function edits available in TORT. The last item to be printed is a summary of cpu time spent on the problem.

\section{Solution Method}

DORT solves the Boltzmann Transport Equation using discrete ordinates techniques. The flux sweep uses one of the Bllowing methods: zeroweighted difference (traditional), theta-weighted difference, or linear 
zero. Scalar and vector versions of these methods are available for user selection. Negative source removal can be implemented to various degrees. Convergence acceleration is achieved using one of two methods: diffusion synthetic acceleration or partial current rebalance. The user can impose convergence criteria using any combination of the following: eigenvalue, pointwise flux (inner iterations), pointwise flux (outer iterations), volumetric flux, and pointwise fission. The second dimension spatial mesh spacing can be a function of the first dimension. The quadrature order can be a function of both space and energy group. In addition to transport theory, DORT has a diffusion theory module that can be used on early iterations of a problem. This can sometimes be helpful in speeding convergence, since a good starting guess can be obtained for the transport calculation using cheap diffusion theory iterations. The input can also be arranged such that only a diffusion theory calculation is performed; in this case, three different triangular geometries can be used (these geometries cannot be used for transport calculations). Details of the DORT theory $\cdots$. be found in Ref. 1.

\section{Accuracy and Limitations}

The accuracy of the DORT code in solving particular types of problems will be addressed in the validation studies performed for those cases. DORT transport calculations are limited to $\mathrm{xz}$ (slab), $\mathrm{rz}$ (cylinder) or $\mathrm{r} \theta$ (circle) geometries (or their 1-d counterparts); it is not possible to exactly represent cubical and cylindrical units together as can be done in most Monte Carlo codes. DORT employs a multigroup energy treatment. The accuracy of the results generated are directly related to the accuracy with which the multigroup cross section library is processed. Since discrete ordinates theory samples in only a finite number of directions, ray effects can create problems in some situations.

\section{Code Source Listing Location}

The source code for DORT is stored under the Scientific Code Management System, which protects it from unathorized changes, and ensures strict quality assurance standards are adhered to. The source code for DORT is stored on the VAX in the following directory: disc\$scms:[scms.source.TORT]. Users who need a copy of the source files should contact the SCMS administrator. 


\section{Program Execution}

Instructions for executing DORT can be found in Ref. 1. A set of test problems has teen developed which tests all major functions of the DORT code and of the utility codes GIP, RTFLUM, BNDRYS, and GRTUNCL. The input and output from these problems are detailed in Ref. 2. The test problem input can be found on the Cray in the directory /u3/b7001/dorttest. The executable modules for DORT and the utility codes are located in the directory /usr/local/scms/bin.

\section{Access Control and Security}

A list of users of the code is maintained by the proprietor. Only those users labeled as cognizant on the proprietor's list may use the code for critical calculations. Changes to the DORT coding are made only by the proprietor, and are implemented by the SCMS custodian after successful execution of the test problem set.

Shell scripts and banners or page headings have been addec to the DORT code. The banners identify the version of the code and the date of compilation. The shell scripts are maintained by the SCMS custodian in accordance with the requirements of Ref. 3.

Technically knowledgeable personnel have been assigned to serve as code proprietor and backup proprietor for the DORT code. These proprietors are members of the user community who are experienced users of the code. The backup proprietor has been identified to ensure continuity of code expertise.

A proprietor's code notebook (Ref, 4) is being maintained in which an ongoing history of code development, alterations, validation, and error corrections is recorded. This notebook will be continually maintained by the code proprietor.

\section{User Qualifications}

User qualification status is divided into the two categories of Apprentice and Cognizant User, as defined in Refs. 5 and 6 . Due to the variety of problems for which DORT may be used, a test will not be required to become a Cognizant User. Instead, the Apprentice will be trained by a Cognizant User. The code proprietor will determine when the Apprentice User has sufficient knowledge and understanding of the 
code to become a Cognizant User. Cognizant Users may be certified only for specific types of calculations or for all calculation types. A list of Apprentice and Cognizant Users will be maintained by the code proprietor.

\section{Discrepancy Reporting}

Cognizant users who find a discrepancy or apparent error in the DORT coding, or who wish to request an upgrade/enhancement of the code, shall file an SCDR with the technical proprietor. The proprietor will report any errors to the code developers at Oak Ridge via a numbered document mailed directly to the developers. ${ }^{*}$ The proprietor will monitor the RSIC newsletter to see when bugs are found or a new version of the code has been released by ORNL.

\section{Manual and Other Documentation}

A user's manual for DORT is in place that details code theory, input and output (Ref. 1), and which also includes a programmer's manual.

A controlled tracking system is in place to inform all cognizant users of coding and system changes in the DORT code. All memoranda issued through this system are numbered and approved by management. The cognizant user list is maintained by the code proprietor.

A Software Requirements Specification and Software Test Plan were developed and approved by the appropriate personnel. A Software Baseline Status Listing is being maintained by the code proprietor. This document will be kept current as revisions and additions to the software documentation are made. All of these documents are maintained by the code proprietor in the task files, along with the task plan and the test problem report (Ref. 2).

\section{Technical Review}

A technical review of this document has been performed in accordance with QAP II-14 of the 1Q34 Manual. The review sheets will be maintained as part of the official task records.

\footnotetext{
* The original developers of TORT are W.A. Rhoades and R.L. Childs, both from Oak Ridge National Laboratory, Oak Ridge, TN 378.31. Dr. Rhoades is still active in the TORT project.
} 
Safety Technology Department

WSR C-T R-94-022

January 1994

DORT Certification Package

Page 7 of 9

\section{Approvals}

The Certification Package Approval form has been signed by the required personnel and comprises the final page of this report. 
Safety Technology Department

W SR C - T R-94-022

January 1994

DORT Certification Package

Page 8 of 9

\section{REFERENCES}

1. W.A. Rhoades and R.L. Childes, An Updated Version of the DOT 4 Oneand Two-Dimensional Neutron/Photon Transport Code, ORNL-5851, Jul. 1982.

2. R.L. Frost, DORT Test Problem Report (U), SRT-APG-930105, Nov. 30, 1993.

3. J.C. Jensen, SCMS Entry Procedure, TP-9n-019, Nov. 15, 1990.

4. R.L. Frost, TORT Proprietors Notebook, WSRC-NB-92-32.

5. J.E. Aull, Qualification of Apprentice Users, TP-90-304, April 15, 1991.

6. J.E. Aull, Qualification of Cognizant Users, TP-90-035, April 15, 1991. 


\section{Software Certification Approval Form}

Page 9 of 9

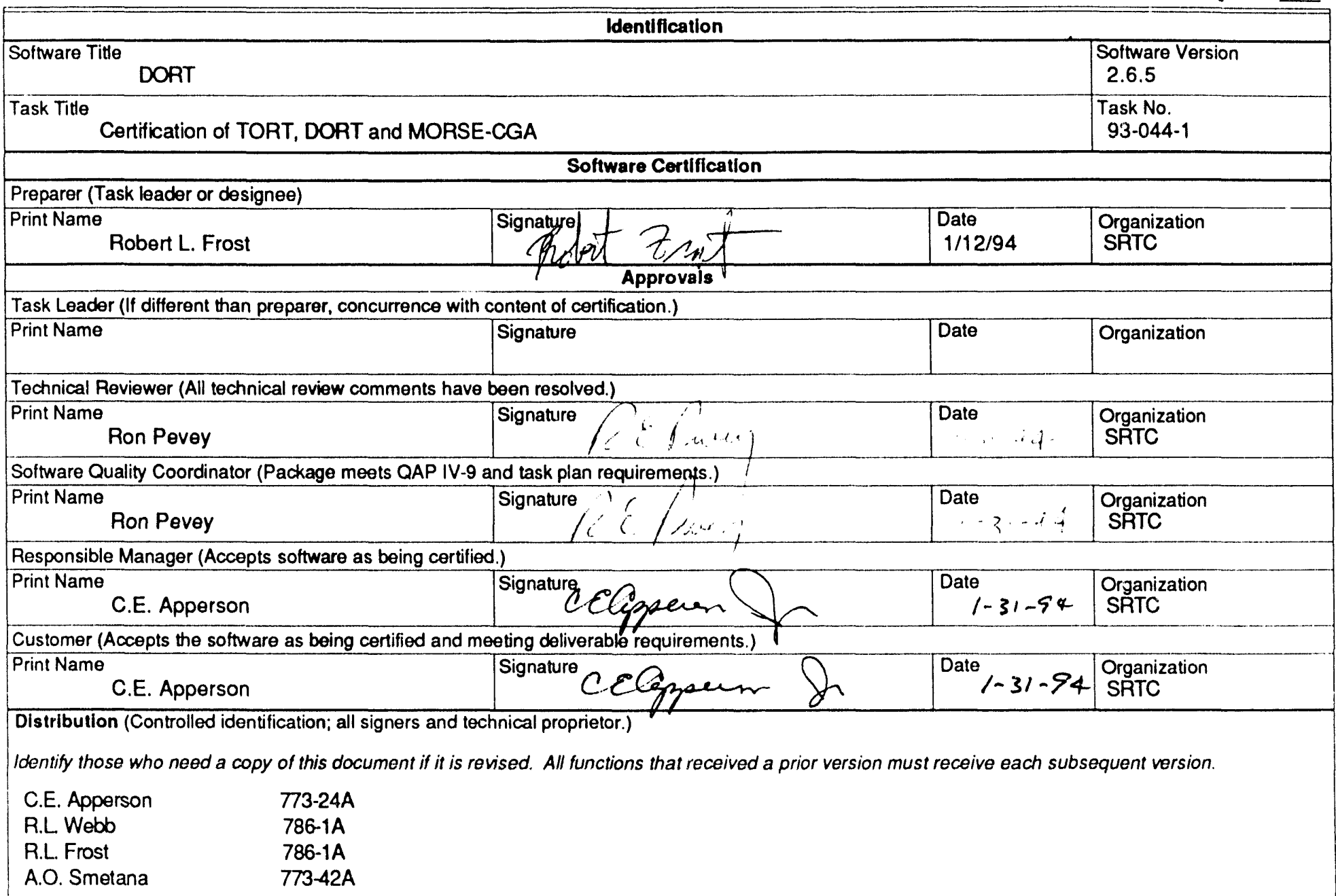




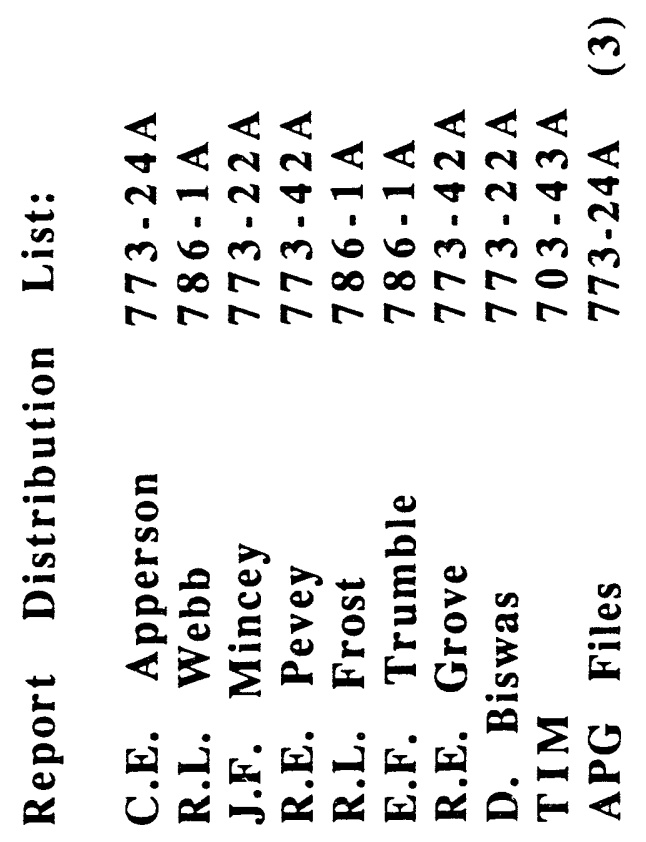




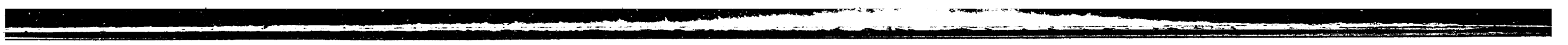

11
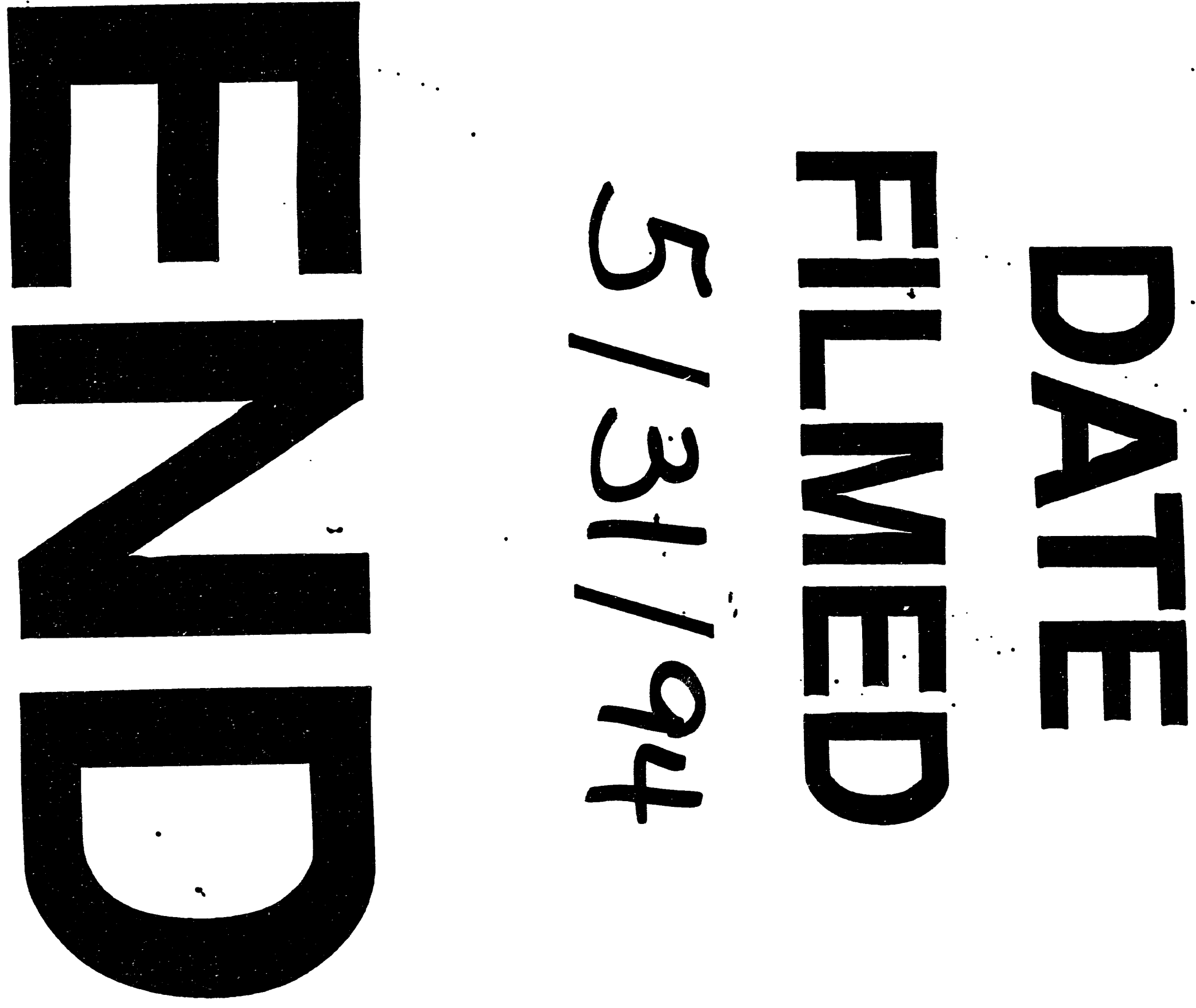

II 


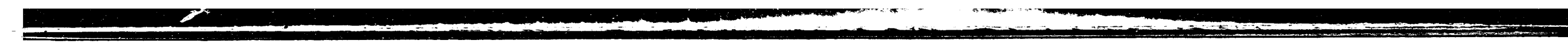

